Disease Focus

Editor's Note: Disease Focus articles provide brief overviews of a neural disease or syndrome, emphasizing potential links to basic neural mechanisms. They are presented in the hope of helping researchers identify clinical implications of their research. For more information, see http://www.jneurosci.org/misc/ifa_minireviews.dtl.

\title{
Advances in the Diagnosis and Treatment of Vestibular Disorders: Psychophysics and Prosthetics
}

\author{
Richard F. Lewis ${ }^{1,2}$ \\ ${ }^{1}$ Department of Otology and Laryngology and ${ }^{2}$ Department of Neurology, Harvard Medical School, Boston, Massachusetts 02114
}

\begin{abstract}
Although vestibular disorders are common and often disabling, they remain difficult to diagnose and treat. For these reasons, considerable interest has been focused on developing new ways to identify peripheral and central vestibular abnormalities and on new therapeutic options that could benefit the numerous patients who remain symptomatic despite optimal therapy. In this review, I focus on the potential utility of psychophysical vestibular testing and vestibular prosthetics. The former offers a new diagnostic approach that may prove to be superior to the current tests in some circumstances; the latter may be a way to provide the brain with information about head motion that restores some elements of the information normally provided by the vestibular labyrinth.
\end{abstract}

\section{Introduction}

Diseases that affect the peripheral or central vestibular system are very common and are responsible for substantial morbidity. Many of these disorders remain difficult to diagnose and often are only minimally amenable to medical or surgical therapy. Here, I provide a brief overview of vestibular physiology and pathophysiology and then discuss two topics that offer the promise of significant diagnostic and therapeutic advances-vestibular psychophysics, an intriguing way to diagnosis both peripheral and central vestibular disorders, and vestibular prosthetics, which could treat patients with peripheral vestibular damage by providing information about head motion and orientation directly to the brain through electrical stimulation of the vestibular afferent nerves.

Received Sept. 19, 2014; revised Jan. 27, 2015; accepted Jan. 28, 2015.

This work was supported by the National Institutes of Health (Grants DC8362, DC13069, DC6909) and the Med El Corporation. I thank Dan Merfeld and Csilla Haburcakova.

The author declares no competing financial interests.

Correspondence should be addressed to Richard Lewis, 243 Charles Street, Boston MA 02114.E-mail: Richard_lewis@meei.harvard.edu. DOI:10.1523/JNEUROSCI.3922-14.2015

Copyright $\odot 2015$ the authors $\quad 0270-6474 / 15 / 355089-08 \$ 15.00 / 0$

\section{Overview of the vestibular system Function}

The peripheral vestibular system consists of the vestibular labyrinth and the vestibular portion of the eighth cranial nerve (for review, see Liberman et al., 2010). Three mutually perpendicular semicircular canals transduce angular head velocity and two otolith organs (the saccule and utricle), which are also approximately orthogonal, sense the vector sum of gravity and linear acceleration (gravito-inertial acceleration, GIA). These physical parameters are transduced by the stereocilia of the hair cells (Torre et al., 1995) that are embedded in the canal's cupula (the cristae) and the ototlith organ's otoconial membrane (the maculae). The semicircular canals are mechanical high-pass filters and temporal integrators so, over the physiologic range of frequencies, each cupula's deflection is proportional to the filtered component of the angular head velocity that is parallel to the canal's rotational axis. All hair cells in each canal are aligned so deflection of the cupula bends all stereocilia in that cristae in one of two directions, resulting in either a decrease or increase in the primary vestibular afferent's firing rate. The three canals in each ear can therefore sense angular head velocity in three dimensions and provide the brain this information by modulating the discharge rate of the ampullary nerves about their nonzero resting rates. A semicircular canal prosthesis could therefore approximate normal canal function by increasing or decreasing the rate of electrical stimulation applied to the canal ampullary nerves based on the head's angular velocity. The otolith organs' maculae are sensitive to gravity and linear acceleration and, with the head upright, they lie in planes approximately parallel to gravity (saccule) and the ground (utricle). Unlike the canals, the stereocilia in different hair cells are not aligned, but rather are oriented radially and reverse their orientation at the striola. Head tilt or translation therefore generates a complex pattern of modulation in the firing rates of nerve fibers innervating the otolith organs, so an otolith prosthesis would need to provide much more complex electrical stimulation than a canal prosthesis (Suzuki et al., 1969).

The central vestibular system in the brainstem and cerebellum has four principal features: (1) inhibitory commissural connections between the vestibular nuclei 
on each side result in a "push-pull" mechanism whereby head rotation both excites and disinhibits the ipsilateral vestibular nuclei; (2) a temporal integrator called velocity storage improves the low-frequency dynamics of the central angular velocity signal and mediates the otolith signal's effects on canal rotational cues, thereby suppressing the postrotational signal whenever the head's rotational axis is not aligned with gravity; (3) the cerebellar nodulus and uvula synthesize canalmediated rotational and otolith-mediated GIA cues and segregate the GIA signal into its tilt and translational components and these regions of the cerebellar vermis also tonically inhibit the velocity storage network in the brainstem via Purkinje cell projections to the vestibular nuclei; and (4) the cerebellar flocculus and ventral paraflocculus underlie the adaptive modification of vestibular-mediated eye movements. Central processing in infratentorial structures generates relatively accurate estimates of the head's angular velocity, linear acceleration, and orientation relative to gravity (Angelaki and Yakusheva, 2009). These neural estimates contribute to three behaviors: perception of head motion and orientation, eye movements that stabilize images on the retina during head motion (the vestibulo-ocular reflex or VOR), and postural reflexes. Vestibular perception forms the basis of psychophysical testing and reflects neural processing in the regions of the thalamus and cerebral cortex that receive projections from the vestibular nuclei and the cerebellum. The location of the "vestibular cerebral cortex" in humans remains controversial (Kahane et al., 2003), but fMRI, electrical stimulation, and other methods show that these cortical areas broadly correspond to locations in the cerebral cortex of animals (located primarily in the insular, parietal, and temporal regions) that receive vestibular inputs and are involved in multisensory integration (Lopez and Blanke, 2011).

\section{Dysfunction}

Vestibular disorders can be classified as acute, chronic, and episodic (Bisdorff et al., 2009). Acute disorders begin suddenly, usually with severe vertigo, nausea, and ataxia, and are typically due to permanent damage in the peripheral or central vestibular system. Compensation in the brain (Peusner et al., 2012) suppresses the vertigo within days and gradually improves (but never fully corrects) the dynamic vestibular deficits, which manifest as imbalance and dizziness provoked by head motion, visual flow stimuli, and changes in head orientation. Acute peripheral damage is most commonly due to viral infection or reactivation and the associated inflammation (Beyea at el., 2012) and can affect the vestibular system (vestibular neuritis) or the vestibular and auditory systems (labyrinthitis). Although these terms imply pathological localization, it is uncertain whether these syndromes damage the labyrinth (killing hair cells), the afferent nerve (killing peripheral neurons), or both. Acute central damage is usually vascular in origin. Interestingly, lesions that affect the brainstem or cerebellum cause dizziness, but damage to vestibular regions of the cerebral cortex does not (except for possible rare exceptions; Brandt et al., 1995). As expected, recovery from central lesions is usually less complete than with peripheral lesions because the brain structures required for compensation are often damaged.

Chronic disorders are progressive and present with gradually worsening imbalance and head motion intolerance. Chronic peripheral disorders that affect one ear are usually slowly growing lesions that damage the labyrinth or afferent nerve, such as a vestibular schwannoma. Chronic peripheral disorders are more typically bilateral and can be due to ototoxins, aging, or other causes. Aside from structural lesions that damage the eighth nerve, chronic disorders primarily kill hair cells in the labyrinth, so these patients may benefit from a vestibular prosthesis because the afferent innervation of the labyrinth should remain electrically excitable despite hair cell loss and because bilateral deficits result in more severe symptoms than unilateral lesions. Chronic central disorders are usually degenerative and most commonly are inherited or sporadic spinocerebellar atrophies, but rarely are caused by slowly growing brain tumors, toxins, or vitamin deficiencies.

Episodic disorders cause recurrent vertigo because of abrupt fluctuations in vestibular function. Vestibular function is often largely preserved with episodic syndromes, so these disorders can be the most difficult to diagnose using standard vestibular tests. Developing new diagnostic approaches is therefore particularly important for this large patient population. Meniere's disease (Merchant et al., 2005) is one of the most common episodic peripheral disorders (prevalence of $0.2 \%$ ); its cause is unknown and it cannot be diagnosed until it has progressed significantly (e.g., after hearing loss develops). Episodic central vestibular disorders are dominated by vestibular migraine (VM; Kayan and Hood, 1984), a common vari- ant of migraine that occurs in $>1 \%$ of the population. In VM, migraines present with dizziness in addition to or instead of headaches and VM is responsible for about $50 \%$ of dizziness in children and about $9 \%$ in adults (Lempert and Neuhauser, 2009). The mechanism(s) that relate migraine to the vestibular system remain uncertain despite (or because of) the extensive interconnections between the brain regions that generate migraine and the vestibular system (e.g., the reciprocal innervation of the dorsal raphe nucleus and locus ceruleus with the vestibular nuclei; for review, see Furman et al., 2013). Other episodic central disorders are quite rare and include inherited channelopathies and seizures generated by foci within the vestibular cerebral cortex.

\section{Diagnosis of vestibular disorders: psychophysics}

\section{Approaches to vestibular testing}

Vestibular testing requires a stimulus to activate the labyrinthine end organ(s) and measurement of a vestibular-mediated output (Fife et al., 2000). The lateral canals' function is assessed by activating them with a thermal (caloric) stimulus or with rotation and by recording eye movement (VOR) responses (Curthoys, 2012). A newer approach involves head-thrust testing using high acceleration head-onbody rotations in the three primary canal planes as the stimuli and the VOR as the output (MacDougall et al., 2013). The otolith organs are assessed with vestibular evoked myogenic potential (VEMP) tests using sound or vibration to activate the saccule (cervical VEMP) or the utricle (ocular VEMP) and measure cervical or ocular muscle evoked electrical responses, respectively (Young, 2013). Caloric and VEMP tests activate one labyrinth at a time, so they are particularly useful when localizing dysfunction to one ear is critical (e.g., when guiding ear surgery). These tests can also be abnormal in both ears, suggesting bilateral dysfunction. In contrast, all tests using motion stimuli simultaneously modulate activity in both ears, so they generally offer less localizing information, although they can almost always segregate unilateral from bilateral damage. Head-thrust tests largely overcome this deficiency by using high-acceleration rotations that drive the afferent discharge rate from one ear to zero, producing asymmetric VOR responses that are smaller when the head is rotated in the direction that activates the damaged canal.

Because $30 \%$ of patients with vestibular symptoms cannot be diagnosed using 


\section{Perceptual thresholds}

A
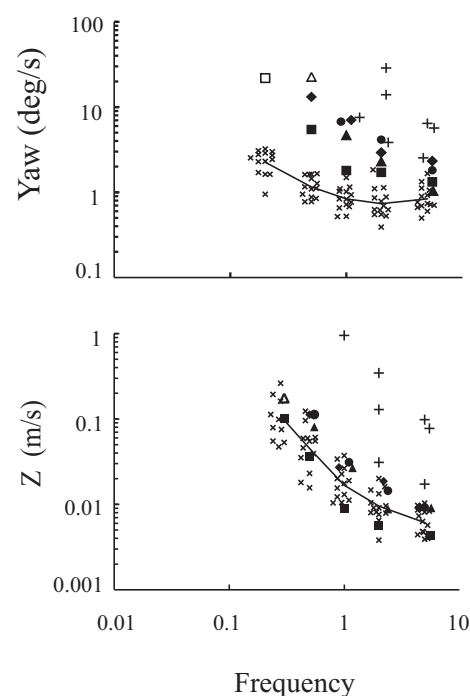

Peripheral dysfunction
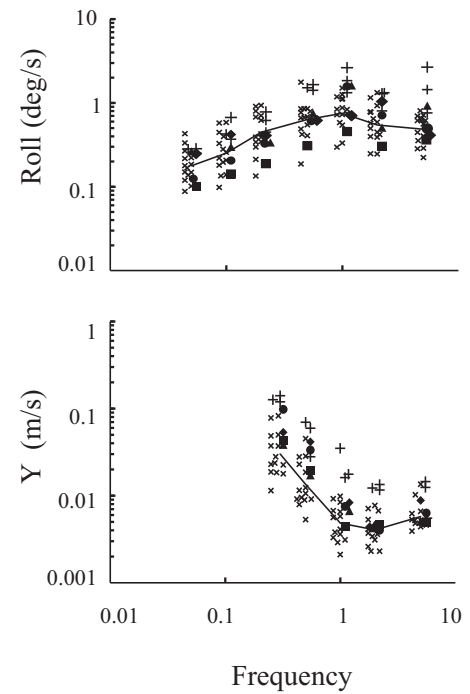

B

Migraine

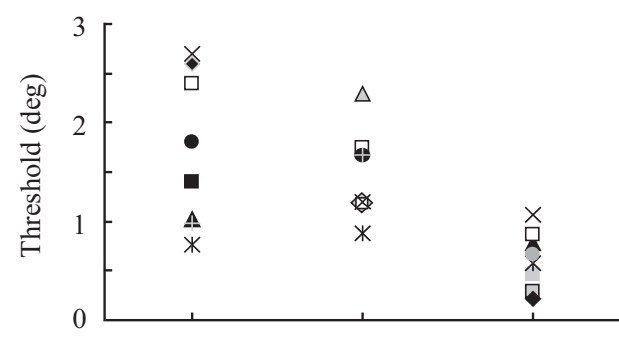

Normal Migraine Vestibular

Figure 1. A, Perceptual thresholds in normal subjects ( $X$ 's fit by line), patients with no vestibular function ( + 's), and patients with idiopathic bilateral vestibulopathy (circular and square icons) for yaw rotation, roll tilt, $Z$ (superior-inferior) translation, and $Y$ (interaural) translation (reprinted with permission from Priesol et al., 2014). $\boldsymbol{B}$, Perceptual thresholds (in degrees) during roll tilt about an earth-horizontal axis at a frequency of $0.1 \mathrm{~Hz}$ for 8 subjects who were normal, had a history of migraine, or a history of vestibular migraine, all tested while asymptomatic (reprinted with permission from Lewis et al., 2011b).

currently available tests (Agrawal et al., 2009), research has focused on developing new ways to evaluate vestibular function. Current tests are probably insensitive because patients primarily experience perceptual symptoms (e.g., vertigo), whereas tests evaluate vestibulo-ocular and spinal reflexes rather than vestibular-mediated perception. Furthermore, psychophysical studies probe the thalamic and cerebrocortical regions and could provide diagnostic information unavailable at the vestibulo-ocular or vestibulo-spinal levels. Specifically, different afferent signals could be supplied to supratentorial and infratentorial structures, these brain regions could process vestibular inputs differently, or dysfunction in supratentorial processing could be directly responsible for vestibular symptomatology. All three of these putative mechanisms are potentially contributory because neurons in the vestibular nuclei that project to the thalamus differ from those that project to the ocular motor nuclei (Cullen, 2012); behavioral studies indicate that the perception of motion is primarily based on integrating canal and otolith cues, whereas eye movements are primarily determined by head motion frequency (Merfeld et al., 2005) and fMRI of patients with vestibular symptoms can show abnormalities isolated to supratentorial structures (Russo et al., 2014).
Vestibular psychophysics

Psychophysical testing can quantify several elements of the vestibular percept. Perceptual thresholds are the smallest vestibular stimulus the brain can distinguish from the noise inherent in vestibular processing (Grabherr et al., 2008). Figure $1 A$ shows perceptual thresholds for normal subjects ( $X$ 's) and patients with no vestibular function (+'s) as a function of frequency for motions that isolate the canals (yaw rotation) or otoliths [ $Y$ (interaural) and $Z$ (superior-inferior) translation], and for combined canal-otolith stimulation (roll tilt; Valko et al., 2012; Priesol et al., 2014). As expected, thresholds were larger in subjects with no vestibular function for all motion protocols, but this difference was most pronounced for yaw rotation and $Z$ translation. Patients with peripheral vestibular damage should have thresholds that fall between the boundaries set by the normal and vestibularabsent subjects for one or more motion paradigms, depending on the distribution of damage. The peripheral disorder called idiopathic bilateral vestibular hypofunction (iBVH; Baloh et al., 1989), for example, is characterized by death of hair cells in the vestibular labyrinth and functional deficits in this disorder have been evaluated using combinations of head rotation, caloric, and VEMP tests. Although the re- sults of these studies have been contradictory (Zingler et al., 2008; Fujimoto et al., 2009), iBVH patients tested with perceptual thresholds (squares/circles in Fig. 1A) show a consistent pattern of changes suggesting that labyrinthine damage is primarily localized to the lateral canals and utricles (as evidenced by increased thresholds for yaw rotation and low-frequency $Y$ translation; Priesol et al., 2014). Further studies are needed to compare the sensitivity of perceptual and reflexive measures to identify peripheral vestibular damage, for example, comparing $Z$ and $Y$ axis thresholds with cervical and ocular VEMPs, respectively (Agrawal et al., 2013).

The most common central vestibular disorder is VM and interictal thresholds in these subjects appear to be abnormally low during midfrequency roll tilt (Lewis et al., 2011a, 2011b; Fig. 1B). Control studies using roll rotation while supine (canal-only stimulus) and very slow, "quasi-static" roll tilt (otolith-only stimuli) demonstrated equivalent thresholds in the VM, migraine, and normal groups (Lewis et al., 2011a). Although these results are preliminary, they suggest that abnormally low roll tilt perceptual thresholds may distinguish VM from control groups and could become a pathognomonic finding for this disorder, which currently lacks specific diagnostic findings. This threshold reduc- 
tion is consistent with the more general sensitization to sensory stimuli associated with migraine (Schwedt, 2013) and the specificity to roll tilt at midfrequencies, where the contribution of nonlinear interactions between canal and otolith inputs are prominent, suggests that the central synthesis of canal and otolith signals may be the underlying abnormality (King et al., 2014). Because canal-otolith integration occurs in the cerebellar nodulus and uvula (Angelaki and Yakusheva, 2009), these results suggest a possible anatomic locus for vestibular dysfunction in VM. More generally, disorders such as VM that affect central vestibular processing directly may be the type of clinical vestibular problem most amenable to diagnosis using perceptual thresholds.

The magnitude and dynamics of the vestibular percept can also be measured. In normal subjects, for example, the percept of yaw rotation and the VOR decay similarly over time, implying that both responses share processing by the velocity storage integrator (Bertolini et al., 2011). After a unilateral peripheral lesion, however, the amplitude and dynamics of the rotational percept deviate from the VOR as the percept becomes smaller and decays more rapidly (Cousins et al., 2013). This finding's significance is uncertain but may reflect cerebral mechanisms that suppress the abnormal percept of vertigo, possibly through cortical habituation (Cousins et al., 2013). Consistent with these human studies, our preliminary experiments in rhesus monkeys demonstrated a discrepancy between the duration of the percept of head tilt and the nystagmus evoked by intralabyrinthine electrical stimulation, with the former decaying faster (Lewis et al., 2013a). These results suggest that psychophysical testing could help to explain why vestibular symptoms frequently diverge from objective, reflex-based test results. Patients who lose peripheral vestibular function, for example, remain subjectively dizzier if they have a history of migraines, even though objective measures do not demonstrate a similar discrepancy between vestibulopathic migraine and nonmigraine populations (Wrisley et al., 2002). This could be a clinical analog to these experimental findings showing that the magnitude of patient's percepts/symptoms deviates from their abnormal reflexes/ signs because of changes in thalamic or cerebral processing that are accessible only through perceptual testing.

The brain normally synthesizes vestibular information with visual, auditory, and other sensory and motor cues to gen- erate a stable and accurate percept of head motion and orientation. Psychophysical methods can assess multisensory integration by quantifying the temporal binding window (TBW) for vestibular and nonvestibular sensory cues, defined as the largest time difference between two sensory stimuli where they are still perceived as simultaneous (Vroomen and Keetels, 2010). Prior studies have estimated the TBW for vestibular and auditory stimuli (Barnett-Cowan and Harris, 2009; Chang et at., 2012), for example, and suggest a relationship between the TBW width and the severity of motion sickness because subjects with higher levels of motion intolerance had larger binding windows (Hullar et al., 2012). This observation raises many interesting questions regarding the possible influence of temporal binding on vestibular symptomatology. Do patients experience "dizziness" because they fail to temporally bind vestibular and nonvestibular singals that are from derived from one event or because they abnormally bind sensory cues caused by distinct events? If abnormal TBWs cause vestibular symptomatology, adaptive modification of TBW (Vroomen et al., 2004) may open new therapeutic approaches for patients with these syndromes. Furthermore, multimodal integration of different percepts that can be assessed with temporal binding methods may prove to be abnormal in some patients with dizziness that cannot be diagnosed with any other measure. Chronic subjective dizziness, for example, is a disorder characterized by persistent dizziness without any objective abnormalities (Ruckenstein and Staab, 2009), but it may be that we are measuring the wrong things in these patients.

\section{Treatment of vestibular disorders: prosthetics Overview}

Peripheral vestibular damage is usually permanent and treatment is limited to vestibular physical therapy, which seeks to maximize central compensation (Cabrera Kang and Tusa, 2013). Patients with severe peripheral vestibular deficits, however, usually have persistent visual, postural, and perceptual symptoms despite therapy. To address this problem, increasing interest has focused on the development and implementation of vestibular prosthetics (Dakin et al., 2013). As noted above, this work concentrates on simulating semicircular canal function because of the complex hair cell organization in the otolithic maculae. The guiding principal is that a canal prosthesis that senses angular head velocity and provides this information to the brain by stimulating semicircular canal afferents could potentially improve vestibular-mediated behaviors if the peripheral disorder is characterized by hair cell death but preservation of electrically excitable primary vestibular afferents (Hirvonen et al., 2005).

\section{Technical development}

The prototype canal prosthesis (Gong and Merfeld, 2000) consists of a rate sensor that measures angular head velocity about one rotational axis, an electrode implanted in one canal near the ampulla, and the circuitry and power needed to provide electrical stimulation to the implanted electrode based on the velocity measured by the sensor. To provide bidirectional motion cues to the brain with a unilateral implant, the prototype prosthesis provided a tonic rate of electrical stimulation (250 pulses/s) that was well above the normal baseline firing rate of the canal afferent nerve. It was hypothesized and subsequently demonstrated that the brain adapts to the imbalance in vestibular tone produced by artificially increased tonic firing rates in one ear (Lewis et al., 2013b) and that stimulation could modulate down (to the baseline discharge rate of the afferents, about 100 spikes/s) or up (to their maximal firing rate, about 450 spikes/s) to signal the direction of head rotation away or toward the implanted ear, respectively (Merfeld et al., 2007). The basic unit of stimulation was biphasic, charge-balance current pulses and angular head velocity was encoded by changing the rate that these pulses were applied to the ampullary nerve, similar to normal rate coding of angular head velocity by the canals. Many technical developments have subsequently enhanced the capabilities of the prosthesis: multisite electrodes (Nie et al., 2013; Valentin et al., 2013) provide more precise stimulation with more constrained current paths $(4,5)$; 3D canal prosthetics extended the 1D prototype with three angular velocity sensors, each aligned with the sensitive axis of a canal and controlling the rate of stimulation applied by the electrode implanted in the corresponding canal (Chiang et al., 2011; Dai et al., 2011); and software has been developed that aligns the rotational axis of the eyes to that of the head by combining stimulation from two or three electrodes to correct the eye's axis (Davidovics et al., 2013). 
Transferring information to the brain

Despite extensive study, the optimal way to transfer angular head velocity information to the brain remains uncertain. Although unilateral implantation can provide bidirectional rotational cues by using a relatively high baseline stimulation rate, behavioral measures of the VOR (Lewis et al., 2010) show that the vestibular system rapidly becomes less sensitive to the high-frequency electrical stimulation. Single unit recordings suggest that this reflects reduced sensitivity at the synapse between the primary afferent and the vestibular nucleus neuron in a manner consistent with LTD (Mitchell et al., 2014). Interestingly, plasticity in the commissural connections appear to partially compensate for this LTD because the contralateral neurons contributing to this feedback loop do not show an increased firing rate predicted by depression of the ipsilateral neuron (Mitchell et al., 2015). Studies that have investigated how to extend the prostheses' dynamic range include amplitude coding (Perez Fornos et al., 2014), combined rate and amplitude coding (Davidovics et al., 2012), filtering the velocity signal (Lewis et al., 2010), reducing tonic stimulation rates (Dai et al., 2011), and using DC stimulation to lower baseline discharge rates of the primary afferents (Fridman et al., 2013). It remains unclear which of these approaches will prove to be the most effective.

A second problem is determining whether electrical stimulation can produce activity in primary afferents similar to normal physiologic activity, which may optimize the prostheses' behavioral benefits. Because current paths appear to be highly constrained, afferent activity is probably not uniform throughout the nerve, but rather focused near the stimulation site(s). Furthermore, irregular afferents, which are more phasic, are likely recruited at lower current levels than regular afferents, which are more tonic (Goldberg et al., 1984). To activate fibers relatively independently of their anatomic location or regularity, the prosthesis should therefore provide fairly high currents. Conversely, strong electrical stimuli would likely entrain the afferent fibers so that they discharge in temporal synchrony and preliminary recordings in primary afferents and vestibular nuclei neurons support this contention (Mitchell et al., 2013a). Such nonphysiologic firing patterns could affect vestibular-mediated behaviors and one possible way to disrupt this synchrony would involve superimposing a very high (e.g., $5 \mathrm{kHz}$ ) pulse train on the motion-modulated stimulus. This type of stimulation may generate random spike activity in sensory afferents and desynchronize their discharges, adding noise to the afferent signal (Rubinstein et al., 1999), which could be titrated to potentiate the sensitivity of the prosthesis by inducing stochastic resonance (Collins et al., 1996).

\section{Behavioral experiments}

Behavioral experiments are necessary to determine whether prosthetic stimulation can improve oculomotor, perceptual, and postural performance in subjects with severe vestibular damage. More specifically: Can the prosthesis generate a VOR with normal kinematic features? Can the prosthetic signal can be synthesized with other sensory signals in a manner that recapitulates normal sensory integration? Can it can contribute to complex, multimodal behaviors such as spatial perception and postural control? Another important issue is the behavioral manifestations of a canal prosthesis when there is no complementary otolith input.

$1 \mathrm{D}$ and $3 \mathrm{D}$ prostheses can produce $1 \mathrm{D}$ and $3 \mathrm{D}$ VOR responses that compensate for head motion (Lewis et al., 2010; Dai et al., 2011, Perez Fornos et al., 2014) and these eye movements should reduce the illusion of visual motion (oscillopsia) that vestibulopathic subjects experience during head movements. Although the amplitude of the prosthesis-mediated VOR can be tuned by increasing stimulation currents, its dynamics are not normal because its low-frequency performance is considerably worse than the normal VOR (Lewis et al., 2010). This dynamic abnormality could reflect LTD from the highfrequency tonic stimulation or other nonphysiologic characteristics of the afferent activity such as highly synchronized firing, which could correlate noise in the fibers and thereby reduce the velocity storage integrator's efficacy (Karmali and Merfeld, 2012). Because the VOR primarily contributes to vision during highfrequency head movements, however, the aberrant low-frequency dynamics are probably not functionally significant.

Sensory integration can be evaluated by measuring the effects of the GIA signal provided by the otolith organs and visual signals on prosthetic VOR responses. The "canal-otolith" interaction is a critical aspect of central vestibular processing (Angelaki et al., 1999) because it is considered the mechanism used by the brain to discriminate head tilt from translation. It can be investigated at the oculomotor level by measuring the VOR's spatial orientation characteristics whereby the eye's rotational axis shifts to align with the GIA (Angelaki and Hess, 1994). Similar behavior was observed with the prosthesis because the prosthetic VOR's axis shifted toward alignment with gravity when the head was tilted (Fig. 2A; Lewis et al., 2012). Visual signals must be capable of modifying the prosthetic VOR to optimize its kinematic features and experiments have demonstrated visually mediated adaptation because both the amplitude (gain) and direction (axis) of the eye movement response improves during chronic prosthetic stimulation (Lewis et al., 2010; Dai et al., 2013).

Perceptual responses have been demonstrated in rhesus monkeys trained to perform a subjective visual vertical (SVV) task (rotating a light bar parallel to gravity; Lewis et al., 2008) and then tested with and without prosthetic stimulation. Figure $2 B$ illustrates that electrical stimulation in one posterior canal produced an SVV deviation contralateral to the stimulated ear, consistent with a misperception of roll tilt in the appropriate direction (Lewis et al., 2013a). Furthermore, preliminary data from a monkey with bilateral vestibular ablation showed that SVV responses during dynamic roll tilts improved when prosthetic stimulation was provided (Thompson et al., 2012). Because gravity is normally sensed by the otolith organs, the presumptive mechanism underlying these findings is that the brain temporally integrates the angular velocity signal provided by the prosthesis to yield head position information, the same mechanism postulated to occur in normal subjects (Angelaki and Hess, 1994; Merfeld et al., 1999).

Vestibular signals may contribute to postural control by providing the brain with an accurate estimate of head orientation relative to gravity, which is combined with information encoding head orientation relative to the body to produce an internal estimate of body orientation relative to gravity (Stapley et al., 2006). Because perceptual studies suggest that prosthetic stimulation improves the first step of this process, a reasonable assumption is that it would similarly improve postural control. Little data are available to date to support this contention. In humans, postural sway appears to align with the orientation of the stimulated canal (Phillips et al., 2013), demonstrating that postural responses in humans can be modified with electrical stimulation of individual canals. Furthermore, prosthetic 
Prosthetic stimulation

A
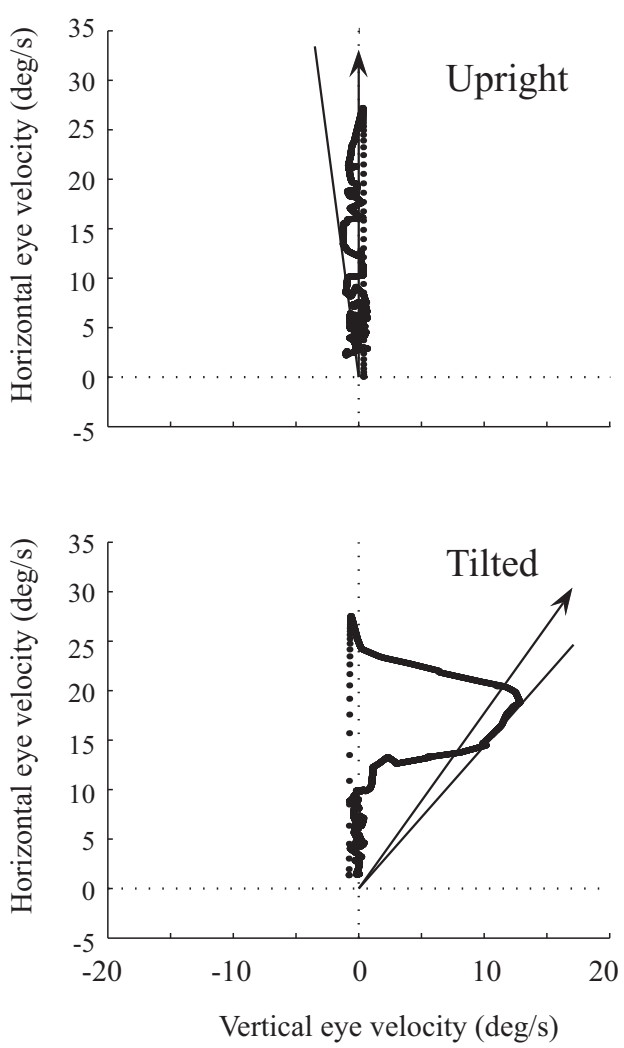

Eye movements
B
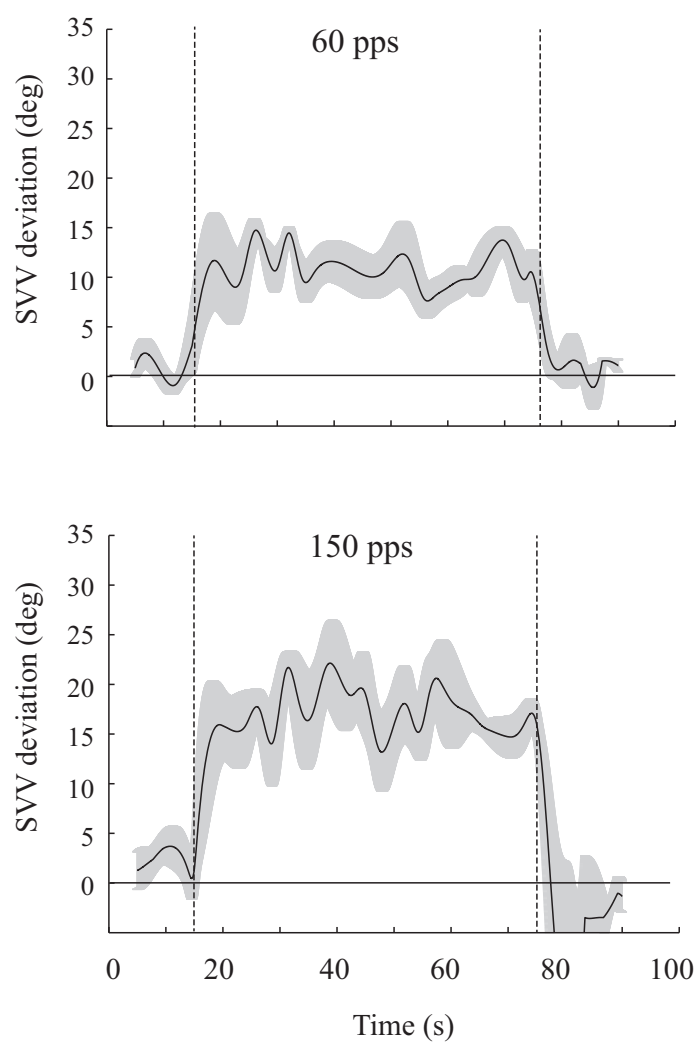

Figure 2. A, Slow phase velocity of eye movements induced in a squirrel monkey when one lateral canal was electrically stimulated with the animal either upright or statically tilted $45^{\circ}$ in roll to a right-ear-down orientation. Arrows indicate the orientation of gravity relative to the head and lines show the maximal shift in the eye's rotational axis. Data are shown in polar coordinates, with horizontal eye velocity on the $y$-axis and vertical velocity on the $x$-axis (reprinted with permission from Lewis et al., 2012). B, SVV response in a rhesus monkey before, during, and after electrical stimulation of one posterior canal at a rate of either 60 or 150 pulses/s. SVV responses deviated away from the stimulated ear during the period of stimulation (which is indicated by the vertical dashed lines). The solid line is the mean and the gray zone is one SE for the SVV response measured during seven stimulation trials for each of the two rates, in a single monkey (reprinted with permission from Lewis et al., 2013a).

stimulation in monkeys generates head turns that appear to have physiologic characteristics and contribute to gaze shifts (Mitchell et al., 2013b). Finally, preliminary data from a vestibulopathic monkey suggests that postural stability during visually guided head turns is improved by prosthetic stimulation (Lewis et al., 2011). Although these reports are encouraging, more definitive perceptual and postural experiments are needed to determine whether subjects with severe vestibular ablation would benefit from prosthetic stimulation in a manner that extends beyond an improved VOR.

How does the brain interpret rotational cues provided by the canal prosthesis without a complementary GIA signal? Almost all natural behaviors modulate activity in the canals and otolith organs concurrently and therefore require central integration of angular velocity and GIA information. Peripheral vestibular dam- age typically affects both canals and otolith organs, however, and if a prosthesis simulates the former but not the latter, it remains unclear whether spatial orientation and postural control will benefit. In fact, decoupling rotational and GIA inputs may result in aberrant estimates of linear acceleration whenever the axis of the head rotation is not precisely aligned with gravity (Angelaki et al., 1999; Merfeld et al., 1999). This is because prosthesis-mediated angular velocity inputs affect estimated head orientation (the " $G$ " in "GIA"; see above), but the GIA signal sensed by damaged otoliths would not modulate normally, so a central estimate of linear acceleration (the "A" in "GIA") would be needed to keep the GIA signal provided by the otoliths consistent with the brain's estimate of head orientation. Preliminary experiments in monkeys indeed show evidence of a misperception of linear acceleration (observable in eye movement responses) when stimulation is provided to one posterior canal. This experiment was done in monkeys with normal inner ear function, so it would be important to determine whether this response persists after a chronic loss of vestibular function, a more clinically relevant situation. This normal central linkage between rotational and GIA signals may be degraded when peripheral vestibular function is absent chronically, similar to the situation astronauts experience after chronic exposure to microgravity (Cohen et al., 2005).

\section{Summary and conclusions}

An emerging literature suggests that psychophysical testing can offer insights into peripheral and central vestibular processing not available from standard vestibulo-ocular and vestibulo-spinal tests. To develop vestibular psychophysics as a diagnostic tool, the principal challenge is to build on the available normative data base 
by applying perceptual methods to specific vestibular problems, an approach that should expand the understanding of vestibular pathophysiology while yielding new ways to diagnose clinical vestibular disorders.

Canal prosthetics can produce an angular VOR that should improve vision during head motion, but it remains unclear whether it can improve spatial orientation and balance. Progress will depend on optimizing the efficacy of information transfer from the sensors to the brain and determining the effects of prosthetic stimulation on perception and posture. An otolith prosthesis or GIA "sensory substitution" device (Vuillerme et al., 2011) may ultimately be required in addition to a canal prosthesis to maximize these more complex behaviors.

\section{References}

Agrawal Y, Carey JP, Della Santina CC, Schubert MC, Minor LB (2009) Disorders of balance and vestibular function in US adults: data from the National Health and Nutrition Examination Survey, 2001-2004. Arch Intern Med 169:938-944. CrossRef Medline

Agrawal Y, Bremova T, Kremmyda O, Strupp M, MacNeilage PR (2013) Clinical testing of otolith function: perceptual thresholds and myogenic potentials. J Assoc Res Otolaryngol 14:905-915. CrossRef Medline

Angelaki DE, Hess BJ (1994) Inertial representation of angular motion in the vestibular system of rhesus monkeys. I. Vestibuloocular reflex. J Neurophysiol 71:1222-1249. Medline

Angelaki DE, Yakusheva TA (2009) How vestibular neurons solve the tilt/translation ambiguity: comparison of brainstem, cerebellum, and thalamus. Ann NY Acad Sci 1164:19-28. CrossRef Medline

Angelaki DE, McHenry MQ, Dickman JD, Newlands SD, Hess BJ (1999) Computation of inertial motion: neural strategies to resolve ambiguous otolith information. J Neurosci 19:316-327. Medline

Baloh RW, Jacobson K, Honrubia V (1989) Idiopathic bilateral vestibulopathy. Neurology 39:272-275. CrossRef Medline

Barnett-Cowan M, Harris LR (2009) Perceived timing of vestibular stimulation relative to touch, light, and sound. Exp Brain Res 198: 221-231. CrossRef Medline

Bertolini G, Ramat S, Laurens J, Bockisch CJ, Marti S, Straumann D, Palla A (2011) Velocity storage contribution to vestibular self-motion perception in healthy human subjects. J Neurophysiol 105: 209-223. CrossRef Medline

Beyea JA, Agrawal SK, Parnes LS (2012) Recent advances in viral inner ear disorders. Curr Opin Otolaryngol Head Neck Surg 20:404408. CrossRef Medline

Bisdorff A, Von Brevern M, Lempert T, NewmanToker DE (2009) Classification of vestibular symptoms: towards an international classification of vestibular disorders. J Vestib Res 19: 1-13. CrossRef Medline

Brandt T, Bötzel K, Yousry T, Dieterich M, Schulze S (1995) Rotational vertigo in em- bolic stroke of the vestibular and auditory cortices. Neurology 45:42-44. CrossRef Medline

Chang NY, Uchanski RM, Hullar TE (2012) Temporal integration of auditory and vestibular stimuli. Laryngoscope 122:1379-1384. CrossRef Medline

Chiang B, Fridman GY, Dai C, Rahman MA, Della Santina CC (2011) Design and performance of a multichannel vestibular prosthesis that restores semicircular canal sensation in rhesus monkey. IEEE Trans Neural Syst Rehabil Eng 19:588-598. CrossRef Medline

Cohen B, Yakushin SB, Holstein GR, Dai M, Tomko DL, Badakva AM, Kozlovskaya IB (2005) Vestibular experience in space. Adv Space Med 10:105-164. CrossRef

Collins JJ, Imhoff TT, Grigg P (1996) Noiseenhanced tactile sensation. Nature 383:770. CrossRef Medline

Cousins S, Kaski D, Cutfield N, Seemungal B, Golding JF, Gresty M, Glasauer S, Bronstein AM (2013) Vestibular perception following acute unilateral vestibular lesions. PLoS One 8:e61862. CrossRef Medline

Cullen KE (2012) The vestibular system: multimodal integration and encoding of selfmotion for motor control. Trends Neurosci 35:185-196. CrossRef Medline

Curthoys IS (2012) The interpretation of clinical tests of peripheral vestibular function. Laryngoscope 122:1342-1352. CrossRef Medline

Dai C, Fridman GY, Davidovics NS, Chiang B, Ahn JH, Della Santna CC (2011) Resoration of $3 \mathrm{D}$ vestibular sensation in rhesus monkeys using a multichannel vestibular prosthesis. Hear Res 281:74-83. CrossRef Medline

Dai C, Fridman GY, Chiang B, Rahman MA, Ahn JH, Davodpvocs MS, Della Santina CC (2013) Directional plasticity rapidly improves 3D vestibulo-ocular reflex alignment in monkeys using a multichannel vestibular prosthesis. J Assoc Res Otolaryngol 14:863-877. CrossRef Medline

Dakin CJ, Elmore LC, Rosenberg A (2013) One step closer to a functional vestibular prosthesis. J Neurosci 33:14978-14980. CrossRef Medline

Davidovics NS, Fridman GY, Della Santina CC (2012) Co-modulation of stimulus rate and current from elevated baselines expands head motion encoding range of the vestibular prosthesis. Exp Brain Res 218:389-400. CrossRef Medline

Davidovics NS, Rahman MA, Dai C, Ahn J, Fridman GY, Della Santina CC (2013) Multichannel vestibular prosthesis employing modulation of pulse rate and current with alignment precompensation elicits improved VOR performance in monkeys. J Assoc Res Otolaryngol 14:233-248. CrossRef Medline

Fife TD, Tusa RJ, Furman JM, Zee DS, Frohman E, Baloh RW, Hain T, Goebel J, Demer J, Eviatar L (2000) Assessment: vestibular testing techniques in adults and children: report of the therapeutic and technology assessment subcommittee of the American Academy of Neurology. Neurology 55: 1431-1441. CrossRef Medline

Perez Fornos A, Guinand N, van de Berg R, Stokroos R, Micera S, Kingma H, Pelizzone M, Guyot JP (2014) Artificial balance: restoration of the vestibulo-ocular reflex in humans with a prototype vestibular neuroprosthesis. Front Neurol 5:66. Medline

Fridman GY, Della Santina CC (2013) Safe direct current stimulation to expand capabilities of neural prostheses. IEEE Trans Neural Syst Rehabil Eng 21:319-328. CrossRef Medline

Fujimoto C, Murofushi T, Chihara Y, Suzuki M, Yamasoba T, Iwasaki S (2009) Novel subtype of idiopathic bilateral vestibulopathy: bilateral absence of vestibular evoked myogenic potentials in the presence of normal caloric responses. J Neurol 256:1488-1492. CrossRef Medline

Furman JM, Marcus DA, Balaban CD (2013) Vestibular migraine: clinical aspects and pathophysiology. Lancet Neurol 12:706-715. CrossRef Medline

Goldberg JM, Smith CE, Fernández C (1984) Relation between discharge regularity and responses to externally applied galvanic currents in vestibular nerve afferents of the squirrel monkey. J Neurophysiol 51:1236-1256. Medline

Gong W, Merfeld DM (2000) Prototype neural semicircular canal prosthesis using patterned electrical stimulation. Ann Biomed Eng 28: 572-581. CrossRef Medline

Grabherr L, Nicoucar K, Mast FW, Merfeld DM (2008) Vestibular thresholds for yaw rotation about an earth-vertical axis as a function of frequency. Exp Brain Res 186:677-681. CrossRef Medline

Hirvonen TP, Minor LB, Hullar TE, Carey JP (2005) Effects of intratympanic gentamicin on vestibular afferents in the chinchilla. J Neurophysiol 93:643-655. Medline

Hullar TE, Malone AK, Smith SB, Chang NN (2012) Migraine, motion sensitivity, and temporal binding. Seeing Perceiving 25:209215. CrossRef

Kahane P, Hoffmann D, Minotti L, Berthoz A (2003) Reappraisal of the human vestibular cortex by cortical electrical stimulation study. Ann Neurol 54:615-624. CrossRef Medline

Cabrera Kang CM, Tusa RJ (2013) Vestibular rehabilitation: rationale and indications. Semin Neurol 33:276-285. CrossRef Medline

Karmali F, Merfeld DM (2012) A distributed, dynamic, parallel computational model: the role of noise in velocity storage. J Neurophysiol 108:390-405. CrossRef Medline

Kayan A, Hood JD (1984) Neuro-otological manifestations of migraine. Brain 107:11231142. CrossRef Medline

King S, Wang J, Priesol AJ, Lewis RF (2014) Central integration of canal and otolith signals is abnormal in vestibular migraine. Front Neurol 5:233. CrossRef Medline

Lempert T, Neuhauser H (2009) Epidemiology of vertigo: migraine and vestibular migraine. J Neurol 256:333-338. CrossRef Medline

Lewis RF, Haburcakova C, Merfeld DM (2008) Roll tilt psychophysics in rhesus monkeys during vestibular and visual stimulation. J Neurophysiol 100:140-153. CrossRef Medline

Lewis RF, Haburcakova C, Gong W, Makary C, Merfeld DM (2010) Vestibuloocular reflex adaptation investigated with chronic motionmodulated electrical stimulation of semicircular canal afferents. J Neurophysiol 103: 1066-1079. CrossRef Medline

Lewis RF, Haburcakova C, Gong W, Lee D, Wall C 3rd, Thompson L, Merfeld DM (2011) Ves- 
tibular prosthesis tested in rhesus monkeys. Conf Proc IEEE Eng Med Biol Soc 2011:22772279. Medline

Lewis RF, Priesol AJ, Nicoucar K, Lim K, Merfeld DM (2011a) Abnormal motion perception in vestibular migraine. Laryngoscope 121: 1124-1125. CrossRef Medline

Lewis RF, Priesol AJ, Nicoucar K, Lim K, Merfeld DM (2011b) Dynamic tilt thresholds are reduced in vestibular migraine. J Vestib Res 21: 323-330. CrossRef Medline

Lewis RF, Haburcakova C, Gong W, Karmali F, Merfeld DM (2012) Spatial and temporal properties of eye movements produced by electrical stimulation of semicircular canal afferents. J Neurophysiol 108:1511-1520. CrossRef Medline

Lewis RF, Haburcakova C, Gong W, Lee D, Merfeld D (2013a) Electrical stimulation of semicircular canal afferents affects the perception of head orientation. J Neurosci 33:95309535. CrossRef Medline

Lewis RF, Nicoucar K, Gong W, Haburcakova C, Merfeld DM (2013b) Adaptation of vestibular tone studied with electrical stimulation of semicircular canal afferents. J Assoc Res Otolaryngol 14:331-340. CrossRef Medline

Liberman MC, Rosowski JJ, Lewis RF (2010) Physiology and pathophysiology. In: Shucknect's pathology of the ear (Merchant SN, Nadol JB, eds). Hamilton, Ontario: BC Decker.

Lopez C, Blanke O (2011) The thalamocortical vestibular system in animals and humans. Brain Res Rev 67:119-146. CrossRef Medline

MacDougall HG, McGarvie LA, Halmagyi GM, Curthoys IS, Weber KP (2013) Application of the video head impulse test to detect vertical semicircular canal dysfunction. Otol Neurotol 34:974-979. CrossRef Medline

Merchant SN, Adams JC, Nadol JB Jr (2005) Pathophysiology of Meniere's syndrome: are symptoms caused by endolymphatic hydrops? Otol Neurotol 26:74-81. CrossRef Medline

Merfeld DM, Zupan L, Peterka RJ (1999) Humans use internal models to estimate gravity and linear acceleration. Nature 398:615-618. CrossRef Medline

Merfeld DM, Park S, Gianna-Poulin C, Black FO, Wood S (2005) Vestibular perception and action employ qualitatively different mechanisms. I. Frequency response of VOR and perceptual responses during translation and tilt. J Neurophysiol 94:186-198. CrossRef Medline

Merfeld DM, Haburcakova C, Gong W, Lewis RF (2007) Chronic vestibule-ocular reflexes evoked by a vestibular prosthesis. IEEE Trans Biomed Eng 54:1005-1015. CrossRef Medline

Mitchell DE, Dai C, Rahman MA, Ahn JH, Della Santina CC, Cullen KE (2013a) Head move- ments evoked in alert rhesus monkeys by vestibular prosthesis sitmulation: implications for postural and gaze stabilization. PLoS One 8:e78767. CrossRef Medline

Mitchell DE, Della Santina CC, Cullen KE (2013b) Characterization of central vestibular neuron responses during electrical stimulation delivered by a vestibular prosthesis. Soc Neurosci Abstr 265.02.

Mitchell DE, Della Santina CC, Cullen KE (2014) Plasticity at the vestibular afferent to the central neuron synapse: effects of vestibular prosthetic stimulation. Soc Neurosci Abstr 157.10

Mitchell DE, Della Santina CC, Cullen KE (2015) Plasticity within the vestibulo-ocular reflex circuitry: implications for use of vestibular prostheses. Association for Research in Otolaryngology 38th Annual MidWinter Meeting. Baltimore, MD, PS-402.

Nie K, Ling L, Bierer SM, Kaneko CR, Fuchs AF, Oxford T, Rubinstein JT, Phillips JO (2013) An experimental vestibular neural prosthesis: design and preliminary results with rhesus monkeys stimulated with modulated pulses. IEEE Trans Biomed Eng 60:1685-1692. CrossRef Medline

Peusner KD, Shao M, Reddaway R, Hirsch JC (2012) Basic concepts in understanding recovery of function in vestibular reflex networks during vestibular compensation. Front Neurol 3:17. Medline

Phillips C, Defrancisci C, Ling L, Nie K, Nowack A, Phillips JO, Rubinstein JT (2013) Postural responses to electrical stimulation of the vestibular end organs in human subjects. Exp Brain Res 229:181-195. CrossRef Medline

Priesol AJ, Valko Y, Merfeld DM, Lewis RF (2014) Motion perception in patients with idiopathic bilateral vestibular hypofunction. Otolaryn Head Neck Surg 150:1040-1042. CrossRef

Rubinstein JT, Wilson BS, Finley CC, Abbas PJ (1999) Pseudospontaneous activity: stochastic independence of auditory nerve fibers with electrical stimulation. Hear Res 127:108-118. CrossRef Medline

Ruckenstein MJ, Staab JP (2009) Chronic subjective dizziness. Otolaryngol Clin North Am 42:71-77, ix. CrossRef Medline

Russo A, Marcelli V, Esposito F, Corvino V, Marcuccio L, Giannone A, Conforti R, Marciano E, Tedeschi G, Tessitore A (2014) Abnormal thalamic function in patients with vestibular migraine. Neurology 82:2120-2126. CrossRef Medline

Schwedt TJ (2013) Multisensory integration in migraine. Curr Opin Neurol 26:248-253. CrossRef Medline

Stapley PJ, Ting LH, Kuifu C, Everaert DG,
Macpherson JM (2006) Bilateral vestibular loss leads to active destabilization of balance during voluntary head turns in the standing cat. J Neurophysiol 95:3783-3797. CrossRef Medline

Suzuki JI, Tokumasu K, Goto K (1969) Eye movements from single utricular nerve stimulation in the cat. Acta Otolaryngol 68:350 362. CrossRef Medline

Thompson LA, Haburcakova C, Gong W, Lee DJ, Wall C $3^{\text {rd }}$, Merfeld DM, Lewis RF (2012) Responses evoked by a vestibular implant providing chronic stimulation. J Vestib Res 22: 11-15. Medline

Torre V, Ashmore JF, Lamb TD, Menini A (1995) Transduction and adaptation in sensory receptor cells. J Neurosci 15:7757-7768. Medline

Valentin NS, Hageman KN, Dai C, Della Santina CC, Fridman GY (2013) Development of a multichannel vestibular prosthesis prototype by modification of a commercially available cochlear implant. IEEE Trans Neural Syst Rehabil Eng 21:830-839. CrossRef Medline

Valko Y, Lewis RF, Priesol AJ, Merfeld DM (2012) Vestibular labyrinth contributions to human whole-body motion discrimination. J Neurosci 32:13537-13542. CrossRef Medline

Vroomen J, Keetels M (2010) Perception of intersensory synchrony: a tutorial review. Atten Percept Psychophys 72:871-884. CrossRef Medline

Vroomen J, Keetels M, de Gelder B, Bertelson P (2004) Recalibration of temporal order perception by exposure to audio-visual asynchrony. Brain Res Cogn Brain Res 22:32-35. CrossRef Medline

Vuillerme N, Hlavackova P, Franco C, Diot B, Demongeot J, Payan Y (2011) Can an electro-tactile vestibular substitution system improve balance in patients with unilateral vestibular loss under altered somatosensory conditions from the foot and ankle? Conf Proc IEEE Eng Med Biol Soc 2011:1323-1326. Medline

Wrisley DM, Whitney SL, Furman JM (2002) Vestibular rehabilitation outcomes in patients with a history of migraine. Otol Neurotol 23: 483-487. CrossRef Medline

Young YH (2013) Potential application of ocular and cervical vestibular-evoked myogenic potentials in Meniere's disease: a review. Laryngoscope 123:484-491. CrossRef Medline

Zingler VC, Weintz E, Jahn K, Bötzel K, Wagner J, Huppert D, Mike A, Brandt T, Strupp M (2008) Saccular function less affected than canal function in bilateral vestibulopathy. J Neurol 255:1332-1336. CrossRef Medline 